\title{
Perioperative renal function and thoracoabdominal aneurysm repair: Where do we go from here?
}

\author{
Leonard N. Girardi, MD
}

\author{
From the Department of Cardiothoracic Surgery, Weill Cornell Medical College, New York, NY. \\ Disclosures: Author has nothing to disclose with regard to commercial support. \\ Received for publication June 16, 2018; revisions received June 16, 2018; accepted for publication June 18, 2018; \\ available ahead of print Aug 7, 2018 \\ Address for reprints: Leonard N. Girardi, MD, Department of Cardiothoracic Surgery, Weill Cornell Medical Col- \\ lege, 525 E 68th St, M-424, New York, NY 10021 (E-mail: lngirard@med.cornell.edu). \\ J Thorac Cardiovasc Surg 2018;156:2049-50 \\ $0022-5223 / \$ 36.00$ \\ Copyright (C) 2018 by The American Association for Thoracic Surgery \\ https://doi.org/10.1016/j.jtcvs.2018.06.057
}

In this issue of The Journal of Thoracic and Cardiovascular Surgery, Coselli and colleagues ${ }^{1}$ examine the impact of preoperative renal dysfunction on perioperative outcomes and survival in patients undergoing Crawford extent II thoracoabdominal aneurysm (TAAA) repair. With an estimated glomerular filtration rate of $60 \mathrm{~mL} /$ $\min / 1.73 \mathrm{~m}^{2}$ as the definition of chronic kidney disease (CKD) ${ }^{2}$ Coselli and colleagues ${ }^{1}$ identified compromised preoperative renal function in 399 (39.8\%) of their 1003 patients. Not surprisingly, these patients were older and sicker, with a much higher percentage of degenerative aneurysms and a lesser incidence of either connective tissue disorders or dissections as etiology. Interestingly, CKD strongly predicted a composite of adverse events and postoperative renal failure requiring hemodialysis. It did not predict operative mortality, however, a finding contradicting previously published data examining the influence of CKD on a broader cohort of patients undergoing TAAA repair. ${ }^{3,4}$ Propensity analysis of 311 pairs of patients with and without CKD did not change these results. After adjusting for median age, 5- and 10-year survivals were also worse when CKD was present. Although, as Coselli and colleagues ${ }^{1}$ stated, this information is useful when counseling patients on the risks of TAAA repair, would it not be nice if we could actually do something to reduce the incidence of postoperative renal failure and its profoundly negative impact on perioperative and long-term outcomes?

It seems logical that cold crystalloid renal perfusion (CRP) should help. Previous randomized trials have shown the benefits of this strategy when compared with cold blood perfusion in patients undergoing TAAA repair. ${ }^{5}$ In this very large cohort of patients undergoing extent II repair, however, neither patients with CKD nor those without CKD had a reduction in the incidence of acute renal failure requiring hemodialysis when CRP was used as an adjunct. Other methods of renal support have been similarly disappointing in preventing either temporary or permanent renal injury. Partial left heart bypass, ${ }^{3}$ profound hypothermic circulatory

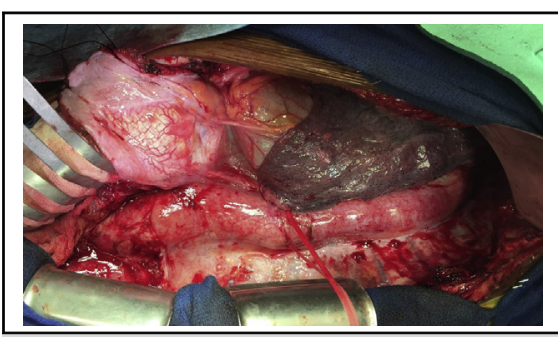

Extent II thoracoabdominal aneurysm

\section{Central Message}

Chronic kidney disease predicts worse outcomes for patients undergoing extent II thoracoabdominal aneurysm repair. Additional adjuncts are needed to reduce this highly morbid complication.

See Article page 2053.

arrest, and a variety of preservation and perfusion solutions have failed to provide significant renal protection. ${ }^{6}$ An aggressive posture toward renal revascularization when renal artery dissection or stenosis is present also sounds like an appropriate strategy to improve renal perfusion; however, surgical bypass, endarterectomy, and endovascular stenting all fail to prevent the need for dialysis in the setting of compromised baseline renal function.

So what else can we do to help those with CKD avoid the $40 \%$ mortality reported for those who have renal failure after undergoing extent II TAAA repair? How can we improve on the $39 \%$ renal recovery rate for those who survive extent II repair after dialysis-dependent renal failure? Renal hypothermia has been the predominant method of reducing oxygen demand and prolonging ischemic tolerance in donor kidneys. ${ }^{8}$ Aortic occlusion without protective adjuncts creates similar stresses to prolonged periods of warm ischemia. When TAAA repair is performed with a simple crossclamp technique, CRP has been shown to reduce the incidence of postoperative renal failure. Granted, no other center will ever report an experience with more than 1000 extent II TAAAs, the cohort at greatest risk for renal failure after aneurysm repair. Nonetheless, most high-volume aneurysm centers use some form of CRP for extent II, III, and IV repairs and continued use is recommended when possible. Most centers that use CRP include mannitol in the cold perfusate, and this hyperosmolar agent may reduce ischemic-reperfusion injury and improve renal 
blood flow by reducing renal endothelial swelling. Goaldirected hemodynamic optimization has been shown to reduce renal dysfunction after infrarenal aneurysm repair ${ }^{10}$ and is likely to be useful in open TAAA repair as well. Further investigation of novel pharmacologic agents for renal protection may add another level of protection for those with CKD.

\section{References}

1. Coselli JS, Amarasekara HS, Zhang Q, Preventza O, de la Cruz KI, Chatterjee S, et al. The impact of preoperative chronic kidney disease on outcomes after Crawford extent II thoracoabdominal aortic aneurysm repairs. J Thorac Cardiovasc Surg. 2018;156:2053-64.

2. KDIGO 2012 clinical practice guideline for the evaluation and management of chronic kidney disease. Kidney Int Suppl. 2013;3:1-150.

3. Girardi LN, Ohmes LB, Lau C, Di Franco A, Gambardella I, Elsayed M, et al. Open repair of descending thoracic and thoracoabdominal aneurysms in patients with preoperative renal failure. Eur J Cardiothorac Surg. 2017; 51:971-7.
4. Coselli JS, LeMaire SA, Preventza O, de la Cruz KI, Cooley DA, Price MD, et al Outcomes of 3309 thoracoabdominal aortic aneurysm repairs. J Thorac Cardiovasc Surg. 2016;151:1323-38.

5. LeMaire SA, Jones MM, Conklin LD, Carter SA, Criddell MD, Wang XL, et al Randomized comparison of cold blood and cold crystalloid renal perfusion for renal protection during thoracoabdominal aneurysm repair. J Vasc Surg. 2009; 49:11-9; discussion 19 .

6. Svennson LG, Coselli KS, Safi HJ, Hess KR, Crawford ES. Appraisal of adjuncts to prevent acute renal failure after surgery on the thoracic or thoracoabdominal aorta. J Vasc Surg. 1989;10:230-9.

7. LeMaire SA, Jamison AL, Carter SA, Wen S, Alankar S, Coselli JS. Deployment of balloon expandable stents during open repair of thoracoabdominal aortic aneurysms: a new strategy for managing renal and mesenteric artery lesions. Eur J Cardiothorac Surg. 2004;26:599-607.

8. Toledo-Pereyra LH. Organ preservation. I. Kidney and pancreas. J Surg Res. 1981;30:165-80.

9. Wynn MM, Acher C, Marks E, Engelbert T, Acher CW. Postoperative renal failure in thoracoabdominal aortic aneurysm repair with simple cross-clamp tech nique and $4^{\circ} \mathrm{C}$ renal perfusion. J Vasc Surg. 2015;61:611-22.

10. Tallgren M, Niemi T, Pöyhiä R, Raininko E, Railo M, Salmenperä M, et al. Acute renal failure and dysfunction following elective abdominal aortic surgery. Eur J Vasc Endovasc Surg. 2007;33:550-5. 